\title{
Extragonadal Germ Cell Tumors in the Mexican Population
}

Guzmán-Casta Jordi ${ }^{1,2 *}$, Baltazar-Contreras Rocío del Carmen², Martínez-Vega Rocío Pamela4, Rubio-Cordero Jairo Aarón², TéllezCampos-Lucía ${ }^{2}$, Padilla-Reyes Nelson Enrique ${ }^{2}$, Carrasco-CaraChards Sonia ${ }^{3}$, Guzmán-Huesca Jorge ${ }^{5}$, Escobar-Gómez Mario²

1 Clinic of Thoracic Oncology Department, Instituto Nacional de Enfermedades Respiratorias, Dr. Ismael Cosío Villegas, Ciudad de México, México 2Clinical Oncology Department, Hospital General de México, Dr. Eduardo Liceaga, Ciudad de México, México

3Facultad de Medicina, Universidad Nacional Autónoma de México, Ciudad de México, México

4Nutritional Department, Hospital General de México, Dr. Eduardo Liceaga, Ciudad de México, México

5Internal Medicine, Bonita Community Health Center, Florida, USA

Correspondence to: Guzmán-Casta Jordi, Clinic of Thoracic Oncology Department, Instituto Nacional de Enfermedades Respiratorias, Dr. Ismael Cosío Villegas, Ciudad de México, México, México; E-mail: jordioncomed@gmail.com

Received date: September 21, 2020; Accepted date: October 2, 2020; Published date: October 10, 2020

Citation: Jordi GC, Rocío del Carmen BC, Rocío Pamela MV, et al. (2020)Extragonadal Germ Cell Tumors in the Mexican Population. J Med Res Surg 1(6): pp. 1-5. Copyright: $(2020$ Jordi GC, et al. This is an open-access article distributed under the terms of the Creative Commons Attribution License, which permits unrestricted use, distribution and reproduction in any medium, provided the original author and source are credited.

\section{ABSTRACT}

Aim: Extragonadal Germ Cell Tumors (EGGCT) are rare malignancies which represent a unique entity because their biology and behavior is substantially different from the tumors whose source is the gonads.

Methods: All cases of Extragonadal Germ Cell Tumors diagnosed and treated the Department of Oncology of the General Hospital in Mexico City between 2015 and 2020 were retrospectively evaluated to determine the clinical and pathological characteristics of the tumors as well as the different treatments utilized and follow-up.

Results: Among a total of 50 patients, the mediastinum was the most frequent location, being found in 46 patients followed by 2 in the retroperitoneal space, 1 in the ethmoidal air cells, and 1 in the pineal gland. The predominant histopathology was a mixed germinal tumor in $82 \%$ of the cases with the rest being pure seminomas. All patients received first-line systemic treatment followed by surgery or second-line treatment according to their initial response to therapy.

Conclusions: Extragonadal Germ Cell Tumors require a multidisciplinary approach to achieve an adequate diagnosis and treatment. The clinical and pathological differences like tumor site, histopathological type, and tumor stage influence the progression-free survival and the global overall survival.

\section{Keywords:}

Extragonadal tumors, Germ cell, Global overall survival, Progression-free survival

\section{Introduction}

Extragonadal Germ Cell Tumors (EGGCT) are rare malignancies arising from anatomical locations different from the gonads.

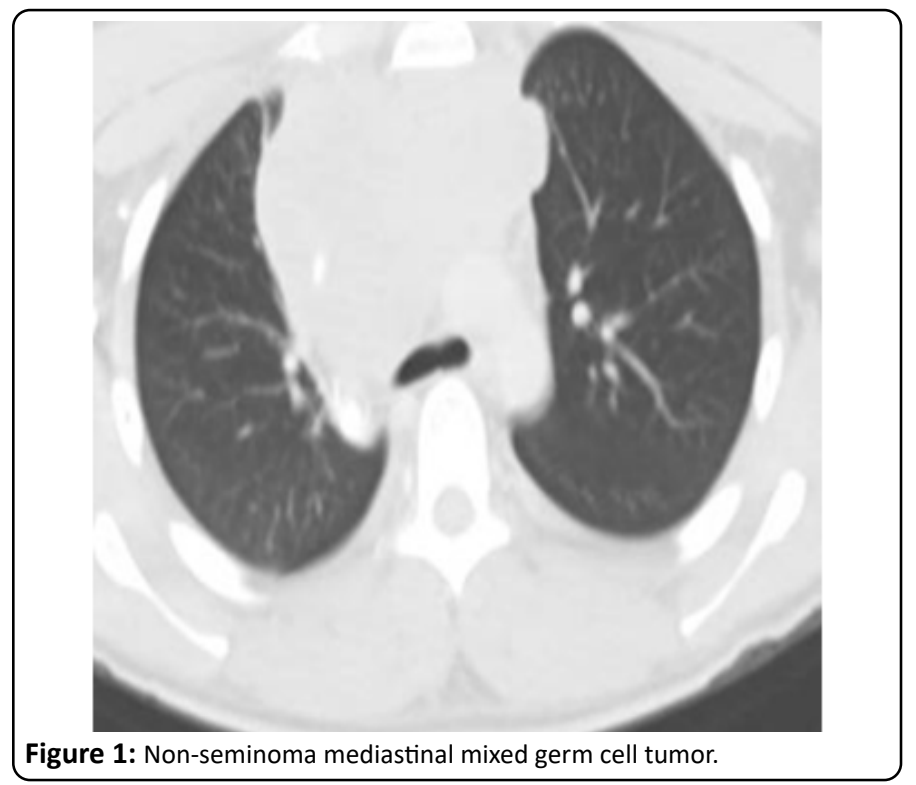

They represent a unique entity because their biology and behavior is substantially different from the tumors whose source is the gonads [1-2].

Approximately between 3\% to 5\% of all Germ Cell Tumors arise from non-gonadal sources, particularly from the mediastinum (Figure 1), the retroperitoneal space (Figure 2), the pineal gland (Figure 3 ), ethmoidal air cells (Figure 4 ), affecting mainly young

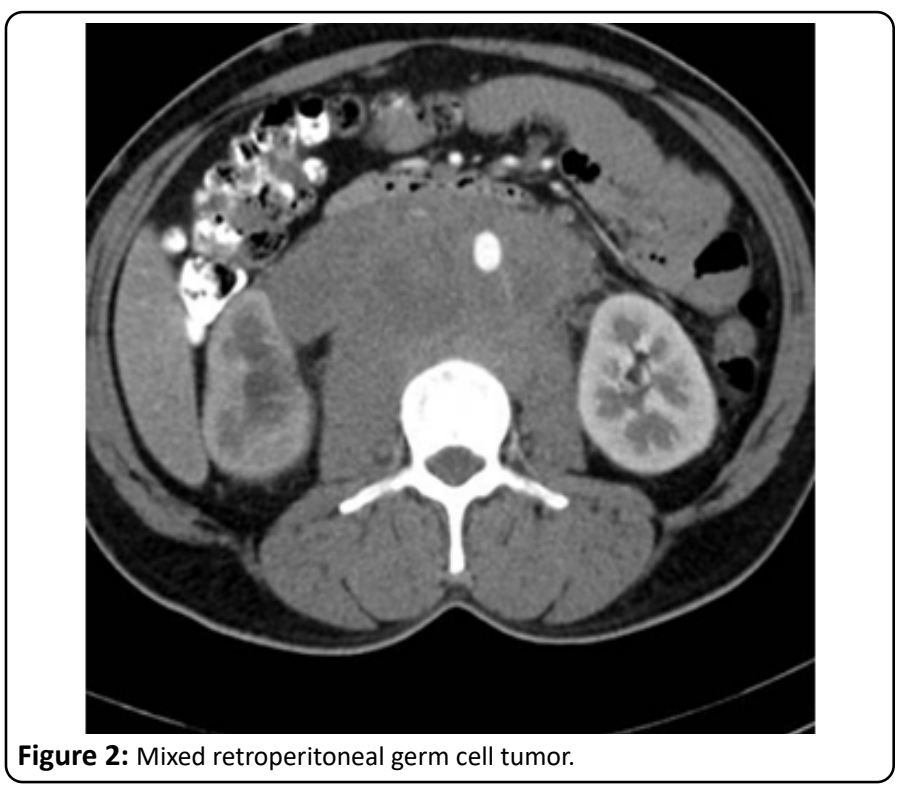


adults in the third decade of life [1].

The cytogenetic, histologic and serologic characteristics of the Extragonadal Germ Cell Tumors are similar to those of the gonadal tumors but important differences exist suggesting that these tumors may be biologically different and as such the Extragonadal Germ Cell Tumors are considered a unique and independent entity requiring a different multimodal approach. Combined management based on multiple agent chemotherapy, surgery and radiotherapy is a pivotal part of the treatment [3-4].

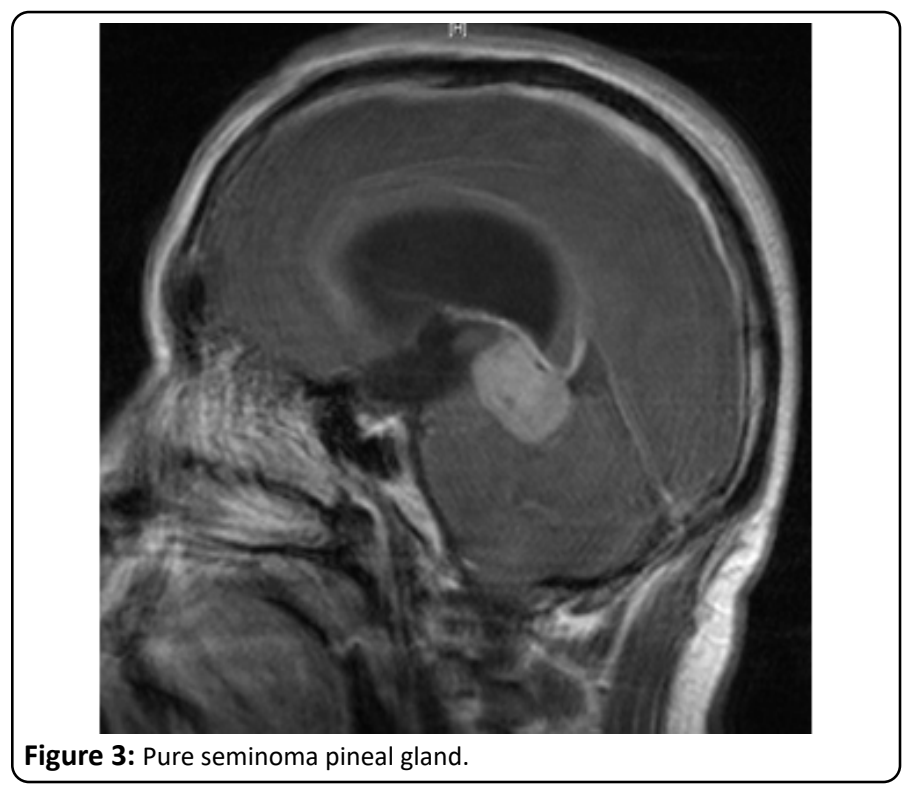

Figure 3: Pure seminoma pineal gland.

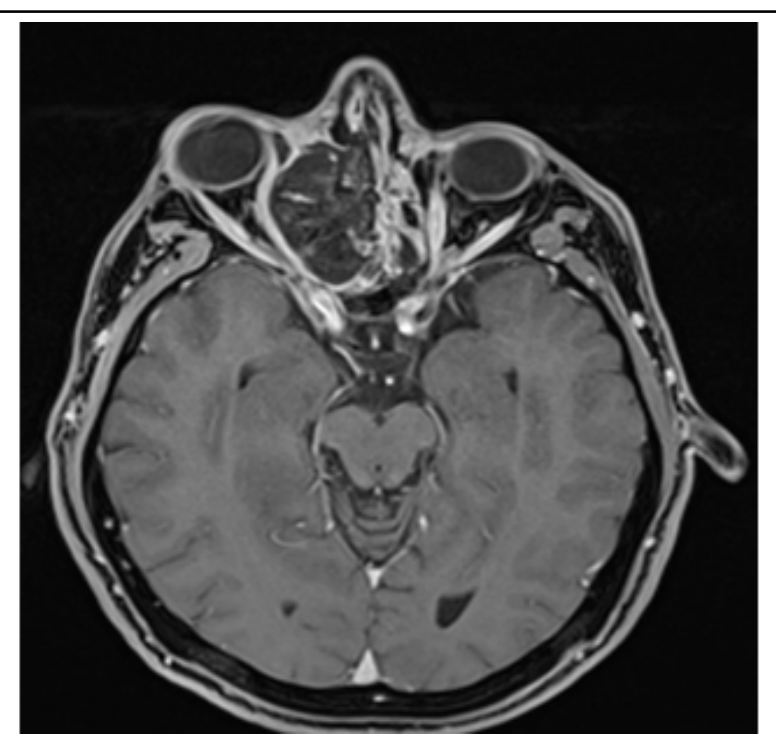

Figure 4: Pure primary seminoma of the ethmoidal air cells.

\section{Clinical Manifestations}

The clinical manifestations are mainly related to the localization of the tumor, patients with mediastinal masses complain of dyspnea (25\%), precordial pain (23\%), and cough (17\%) as the initial presentation followed by fever (13\%), loss of weight $(11 \%)$, superior vena cava syndrome and tiredness and fatigue (6\%). Less common symptoms reported were hoarseness, hemoptysis, and dysphagia (1\%). Patients with retroperitoneal tumors experienced abdominal pain (29\%), back pain (14\%), other symptoms are loss of weight (9\%), fever (8\%), inferior vena cava thrombosis (9\%), palpable abdominal mass $(6 \%)$, cervical lymph node enlargement (4\%), scrotal edema (5\%), gynecomastia and dysphagia (3\%) [5-8].

Metastasis is less frequent with Seminomatous Extragonadal Germ Cell Tumors (40\%) compared to Non-Seminomatous (50\% and $76 \%$ mediastinal and retroperitoneal tumors respectively). The pattern of metastasis varies according to the tumor location and its histology; mediastinal seminomas have mainly metastatic deposits in the cervical lymph nodes while non-seminomatous tumors have lung metastasis in $27 \%$ of the cases. The retroperitoneal seminoma produces metastasis to retroperitoneal lymph nodes $(26 \%)$, mediastinal lymph nodes $(12 \%)$, and cervical lymph nodes (6\%) while the nonseminomatous retroperitoneal tumor causes lung metastasis (49\%), the involvement of the abdominal and cervical lymph nodes (34\% and $18 \%$ respectively), and hepatic metastasis (25\%) [8-10].

\section{Diagnosis}

Because Extragonadal Germ Cell Tumors are not as clinically evident as the Primary Gonadal Tumors the diagnosis is most of the time suspected when symptoms are related to the growth of the tumor in the mediastinum or the retroperitoneal cavity appear.

Apercutaneousfineneedlebiopsyoradiagnosticmediastinoscopy can reveal seminomatous or non-seminomatous elements but sometimes the term "undifferentiated carcinoma" is reported by pathology, in that case, it's very important to obtain serum tumor markers and to request germ specific immunopathology that should result in a more precise diagnosis in almost all the cases [11-14].

\section{Prognosis}

Seminomatous Extragonadal Germ Cell Tumors of the mediastinum and retroperitoneal space carry the same prognosis as their counterpart gonadal tumors, with a 5 years survival of $88 \%$. The prognostic markers used in the gonadal tumors like HGC and LDH levels, the presence of non-pulmonary visceral metastasis, or primary tumor in the mediastinum are equally effective to predict good or intermediate prognosis in primary tumors of the extragonadal source.

Non-seminomatous Germ Cell Tumors have a worse prognosis than the Seminomatous tumors with a 5 years survival rate of $62 \%$ for the retroperitoneal and $45 \%$ for the mediastinal location. The rate of Complete Response with normalization of the tumor markers is $68 \%$ and $64 \%$ respectively for retroperitoneal and mediastinal tumors and the relapse rate is $50 \%$ for the retroperitoneal tumors and $52 \%$ for the mediastinal location [15].

\section{Treatment}

The principles of therapy for Seminomatous and NonSeminomatous Extragonadal Tumors run parallel to those described in the NCCN (National Comprehensive Cancer Network) guidelines for Gonadal Germ Cell Tumors.

The emergent role of chemotherapy in patients with advanced seminomas has led many researchers to use Cisplatin-based therapy as primary treatment. Based on this, patients with good prognosis should be treated with 3 cycles of Cisplatin, Etoposide, and Bleomycin (BEP) and those with intermediate prognosis should receive 4 cycles [16]. 
Patients with large volume seminomas regardless of its location frequently have residual radiographic abnormalities following chemotherapy. The ideal management for patients with residual tumor after chemotherapy remains controversial.

Patients with seminoma and a residual tumor after chemotherapy of more than $3 \mathrm{~cm}$ carry the risk to harbor a viable tumor. In these patients, surgical resection is recommended to determine the nature of the mass and the need for further therapy.

In the case of Non-Seminomatous mediastinal tumors, the consensus is for chemotherapy as the primary line of treatment and because they carry a worse prognosis, a 4 cycles therapy with Cisplatin, Etoposide, and Bleomycin (BEP) is recommended.

If posterior to therapy the serum levels of tumoral markers return to normal, a complete resection of the persistent radiographic abnormalities by an experienced thoracic surgeon is crucial to eliminate any residual tumor. However, and given the rarity of this subgroup of tumors, there is a lack of consensus for treatment strategies. In this study, we retrospectively reviewed our experience with Extragonadal Germ Cell Tumors emphasizing the clinical and pathological characteristics as well as the multimodal therapeutic approach.

\section{Methods}

We conducted a retrospective and descriptive analysis in patients diagnosed with Mixed Extragonadal Germ Cell Tumors between January of 2014 and December of 2019 at General
Hospital in Mexico City. During this period a total of 50 patients were recruited and each one of them was diagnosed through histopathology obtained by biopsy of the tumoral mass. Patients with Primary Gonadal Germ Cell Tumors were excluded from the study. All clinical and pathological details, age, sex, primary location, serum tumoral marker levels, radiographic and surgical reports were obtained through the Hospital Patient Registry. The most frequent primary location was the mediastinum in 46 cases followed by the retroperitoneal cavity in 2 and the ethmoidal air cells and the pineal gland with 1 case respectively.

\section{Results}

After analyzing the clinical data and pathology reports, we observed that the predominant histology was the Mixed Germ Cell Tumor in $82 \%$ of the cases with the rest of the cases being Pure Seminomas. All patients received first-line systemic therapy with Bleomycin, Etoposide and Cisplatin (BEP) with posterior clinical, biochemical, and radiological evaluation. Seven patients were referred for surgical treatment due to persisting residual tumor after chemotherapy and 15 patients underwent a second line of therapy with Paclitaxel, Ifosfamide, MESNA, and Cisplatin (TIP) due to persistence or progression of the disease. 10 of these patients initiated active surveillance as their disease reached a stable status but the other 5 with evidence of progression were treated with Gemcitabine and Oxaliplatin (GemOx) as a third-line therapy.

Response to Treatment

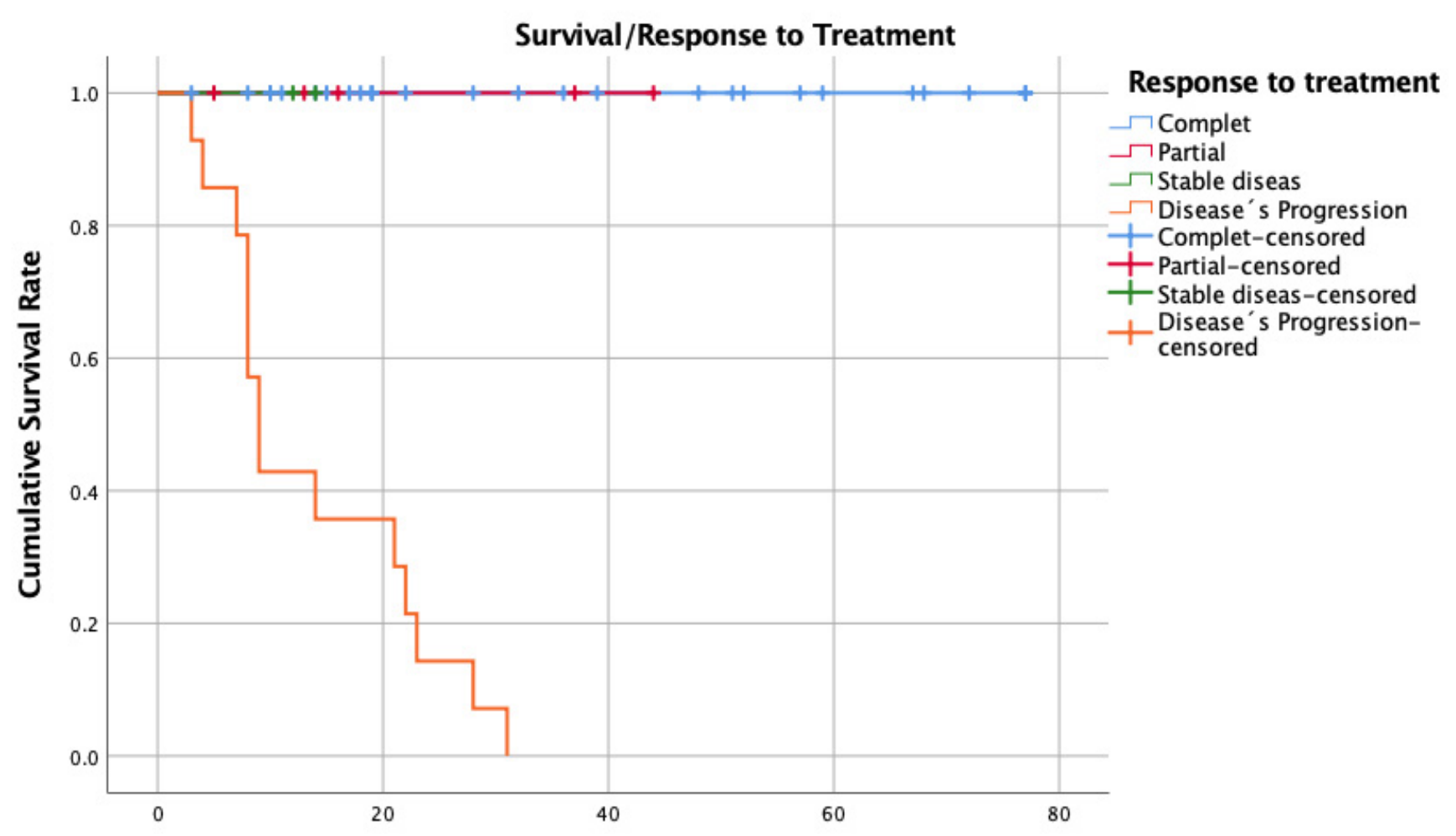

Figure 5: Table of response to treatment

The total of patients with progression of the disease represent $28 \%$ of the total mortality.

\section{Type of Cancer}

Eleven patients of the total of 39 with Non-Seminomatous Tumors died compared to 3 out of 11 in the Seminoma Tumor group

\section{Chemotherapy Treatment}

For mortality, these were the results: 1 out of 7 patients treated with BEP+TIP died as well as 3 out of 5 patients treated with $B E P+T I P+G e m O x .3$ out of 6 patients treated with BEP+RT also 


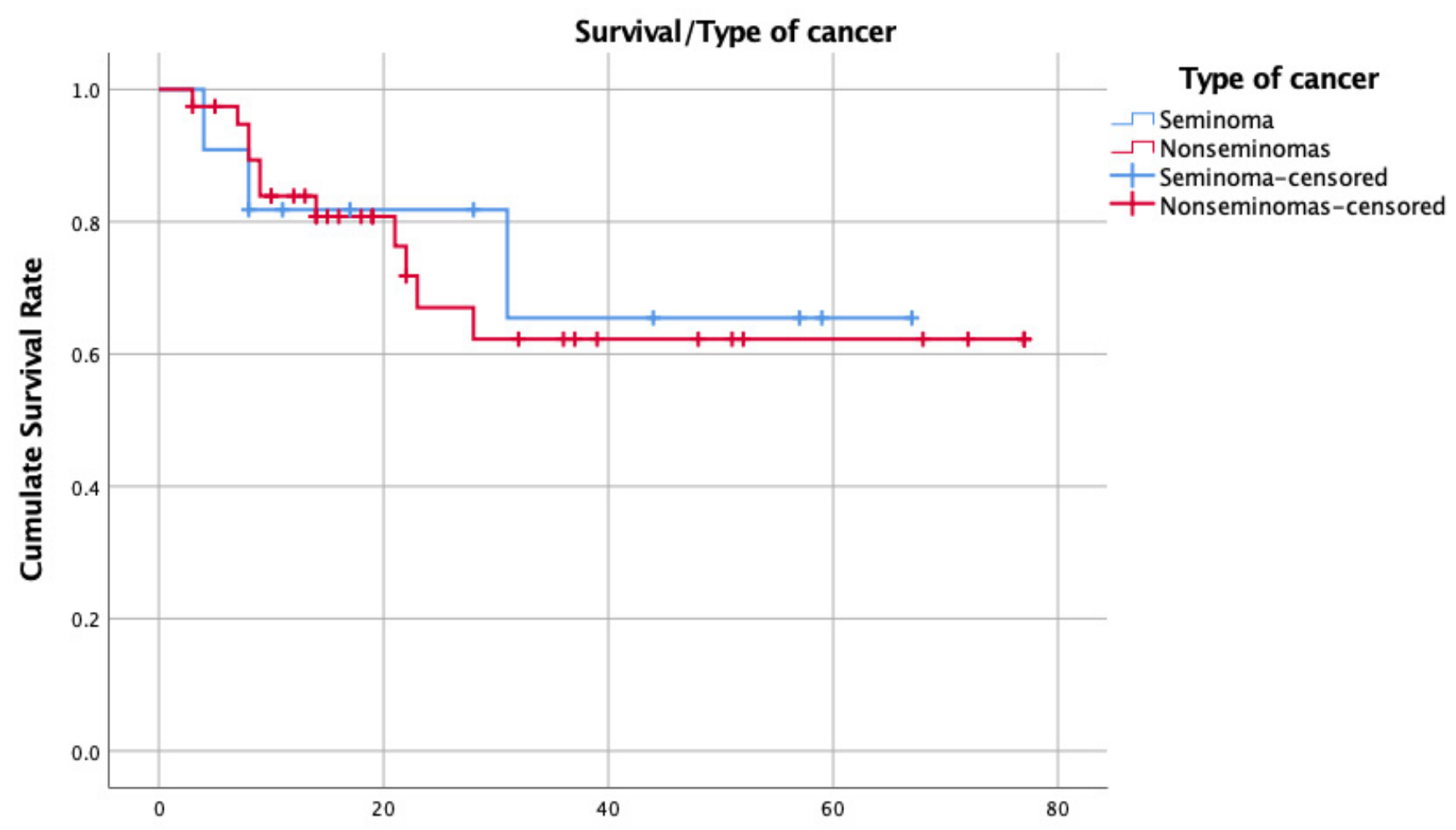

Figure 6: Type of cancer (seminoma or non-seminomatous).

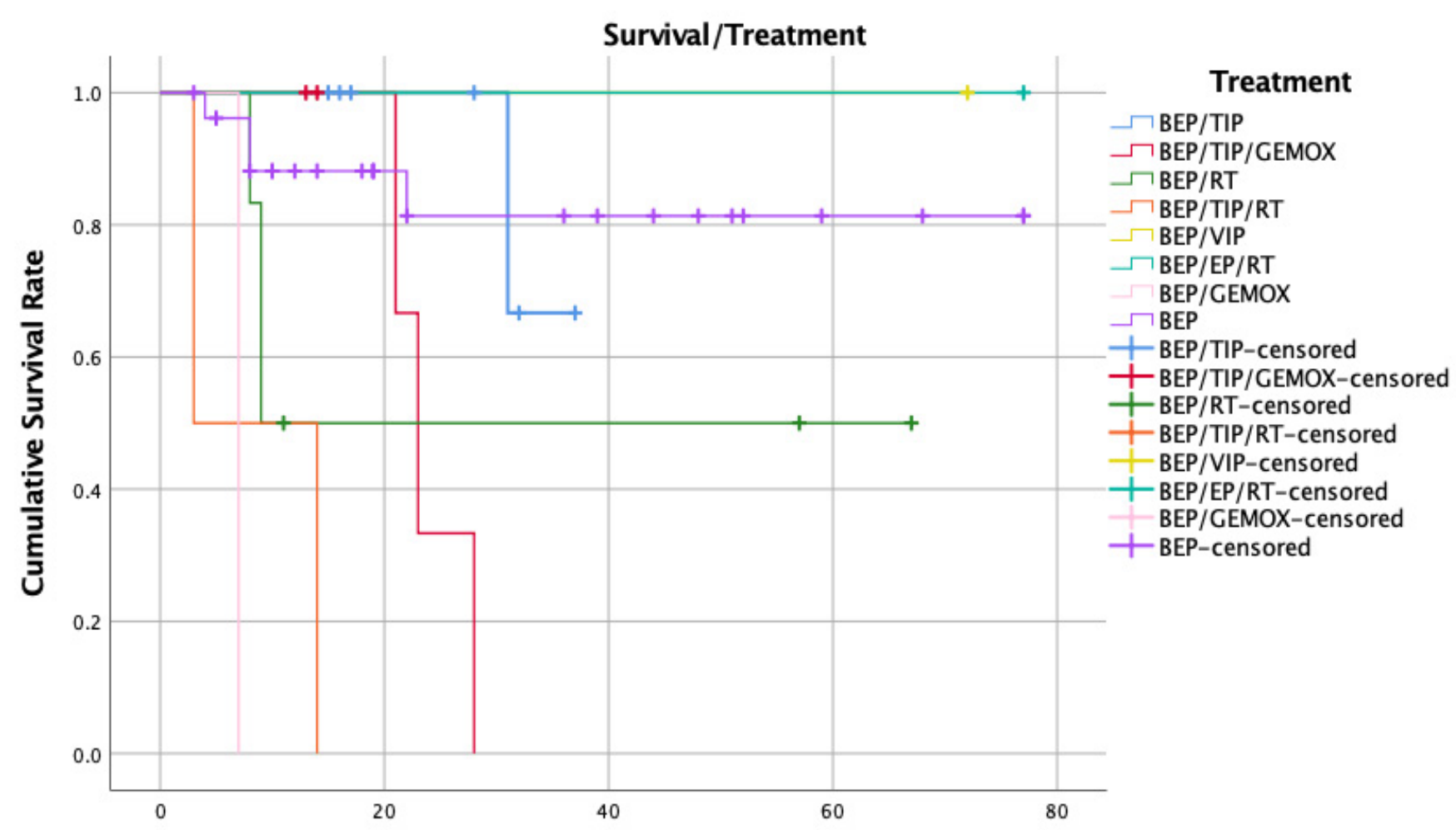

Figure 7: Chemotherapy treatment different modalities.

died and the 2 patients treated with BEP+TIP+RT succumbed to the disease. Of the total of 27 patients who received BEP as therapy 4 of them died. We observed an overall mortality rate of $28 \%$.

\section{Discussion}

Acknowledging that Extragonadal Germ Cell Tumors are rare, to be able to observe 50 patients in a Tertiary Care Hospital is important to gather experience about the disease and although we know the biology of the gonadal and extragonadal tumors and that the latter particularly have a midline presentation, it was interesting to see that up to $82 \%$ of the cases in our series 
were Non-Seminomatous Mixed Germ Cell tumors. These tumors usually require a more intense multimodal management and our patients observed a lower overall survival rate compared to the pure seminomas that accounted for only $18 \%$ of the total tumors. Being Bleomycin, Etoposide and Cisplatin (BEP) the mainstay of therapy for Germ Cell Tumors, those who had at least a partial response to it plus consolidation with Radiotherapy had better survival than those who required second-line therapy with TIP, VIP, or GemOx and with that we conclude that the best outlook for a patient with an extragonadal tumor is for this tumor to be a pure seminoma that responds completely or at least partially to first-line chemotherapy and radiation consolidation to increase the free of disease progression and overall survival.

\section{References}

1. The Global Cancer Observatory 2018.

2. Utz D (1971) Extragonadal Testicular Tumors. J Urol 106(3): pp. 271-274.

3. Collins DH, Pugh RC (1964) Classification and frequency of testicular tumours. Br J Urol 36(Supplementary): pp. 1-11.

4. Stang A, Trabert B, Wentzensen N, et al. (2012) Gonadal and extragonadal germ cell tumours in the United States, 19732007. Int J Androl 35(4): pp. 616-625.

5. Albany C, Einhorn LH (2013) Extragonadal Germ Cell Tumors: Clinical Presentation and Management. Curr Opin Oncol 25(3): 261-255.

6. Cox JD (1975) Primary malignant germinal tumors of the mediastinum: a study of 24 cases. Cancer 36(3): pp. 1162-1168.

7. Shivdasani RA, Kantoff PW (1997) Extragonadal germ cell tumors. In Raghavan D, Scher HI, Leibel SA, Lange PH (ed.): Principles and Practice of Genitourinary Oncology. Philadelphia,
PA: Lippincott-Raven: pp. 751-764.

8. Schmoll HJ (2002) Extragonadal germ cell tumors. Ann Oncol 13(4): pp. 265-272.

9. Bokemeyer C, Nichols CR, Droz JP, et al. (2002) Extragonadal germ cell tumors of the mediastinum and retroperitoneum: results from an international analysis. J Clin Oncol 20(7): pp. 1864-1873.

10. Bokemeyer C, Droz JP, Horwich A, et al. (2001) Extragonadal seminoma: an international multicenter analysis of prognostic factors and long-term outcome. Cancer 91(7): pp. 1394-1401.

11. Raghavan D, Boyer MJ (1996) Malignant extragonadal germ cell tumors in adults. In Horwich A (ed.): Testicular Cancer: Investigation and Management, 2nd edition. London: Chapman \& Hall: pp. 345-367.

12. Greco FA, Hainsworth JD (1997) Management of extragonadal germ-cell tumors. In Ernstoff MS, Heaney JA, Peschel RE (ed.): Urologic Cancer. Oxford: Blackwell Science: pp. 618-626.

13. Droz JP, Horwich A (1996) Extragonadal germ cell tumors. In Vogelzang NJ, Scardino PT, Shipley WU, Coffey DS (ed.): Comprehensive Textbook of Genitourinary Oncology. Williams \& Wilkins: pp. 1070-1074.

14. Hainsworth JD, Einhorn LH, Williams SD, et al. (1982) Advanced extragonadal germ cell tumors. Ann Intern Med 97(1): 7-11.

15. Hidalgo M, Paz-Ares L, Rivera F, et al. (1997) Mediastinal non-seminomatous germ cell tumors (MNSGCT) treated with cisplatin-based combination chemotherapy. Ann Oncol 8(1): pp. 555-559.

16. Goss PE, Schwertfeger L, Blackstein ME, et al. (1994) Extragonadal germ cell tumors. Cancer 73(2): pp. 1971-1979. 